\title{
La renovación biográfica de las "Vidas Españolas e Hispanoamericanas del Siglo XIX"1
}

\author{
Jessica CÁLIZ MONTES \\ Universidad de Barcelona \\ jcalizmontes@gmail.com
}

\begin{abstract}
RESUMEN
El presente artículo analiza la colección "Vidas Españolas e Hispanoamericanas del Siglo XIX" (1929-1942), un proyecto editorial de Espasa-Calpe promovido por Ortega y Gasset y dirigido por el crítico e historiador Melchor Fernández Almagro. Puesto que la colección fue el mejor exponente español de la renovación biográfica conocida como "nueva biografía", llevada a cabo durante las tres primeras décadas del siglo XX en Europa - con autores como Lytton Strachey, Emil Ludwig, André Maurois y Stefan Zweig, entre otros-, en primer lugar se exponen las particularidades de dicha renovación, cuyos principales objetivos eran la desvinculación historiográfica y la autonomía de la biografía como género. En segundo lugar, se aborda la recepción del fenómeno en España en un momento en que la crisis de la novela a la que aludía Ortega y Gasset en Ideas sobre la novela (1925) hizo que la demanda del público se encaminara hacia el género de las biografías. Finalmente, se describen las coordenadas de la colección de Espasa-Calpe, marcadas no sólo por la delimitación a personajes decimonónicos españoles e hispanoamericanos, sino también por la razón vital orteguiana y su magisterio intelectual.
\end{abstract}

Palabras clave: "nueva biografía", Ortega y Gasset, Melchor Fernández Almagro, EspasaCalpe.

\begin{abstract}
This paper analyses the Espasa-Calpe collection "Vidas Españolas e Hispanoamericanas del Siglo XIX" (1929-1942), an editorial project promoted by José Ortega y Gasset and directed by the critic an historian Melchor Fernández Almagro. Inasmuch as the collection was the best Spanish example of the biographical renovation known as "New Biography", brought

${ }^{1}$ El presente trabajo se inscribe en la tesis doctoral en curso "El desarrollo de la 'nueva biografía' en la colección 'Vidas Españolas e Hispanoamericanas del Siglo XIX', de Espasa-Calpe", dirigida por la doctora Marisa Sotelo Vázquez, y financiada mediante una beca del Programa de Formación del Profesorado Universitario del Ministerio de Educación, Cultura y Deporte.
\end{abstract}


about during the first three decades of the twentieth century - with Lytton Strachey, Emil Ludwig, André Maurois and Stefan Zweig, inter alia-, firstly we shall expose the particularities of this renovation, whose main objectives were the historiographic disengagement and the autonomy of biography as a genre. Secondly, we shall explain the reception of the collection in Spain, just when the crisis of the novel which Ortega y Gasset announced in Ideas sobre la novella (1925) had turned the public to biographies. Finally, we shall describe the coordinates of the Espasa-Calpe collection. These were marked not only by the limitation of European and Hispano-American nineteenth-century characters, but also by Ortega's "razon vital" and his intellectual teaching.

Keywords: "New Biography”, Ortega y Gasset, Melchor Fernández Almagro, EspasaCalpe.

Durante las primeras décadas del siglo XX, especialmente a partir de la publicación de los Eminent Victorians (1918) de Lytton Strachey en Inglaterra, la biografía moderna protagonizó un proceso de renovación que permitió la desvinculación historiográfica: dejaba de ser un género menor y subsidiario, y adquiría autonomía con unos rasgos propios y cercanos a los literarios. Las propuestas de revitalización, surgidas principalmente en Inglaterra, Francia y Alemania, dialogaban con las fronteras estilísticas respecto a la historia, la novela y el ensayo.

Este apogeo biográfico de entreguerras conocido como "nueva biografía" o "biografía novelada" tuvo también acogida en la Península entre 1920 y 1940, tal como reconstruye Enrique Serrano Asenjo en Vidas oblicuas: Aspectos teóricos de la nueva biografía en España (1928-1936) (2002). Ante la crisis de la novela a la que hacía referencia José Ortega y Gasset en Ideas de la novela (1925), la demanda del público se encaminó hacia el género biográfico, ya que las vidas de personajes históricos resultaban más atractivas para un determinado sector del público que las prácticas modernistas o los intentos de la novela deshumanizada. En esos años se tradujeron numerosas biografías y estudios literarios extranjeros, a los que se sumaron las primeras iniciativas españolas.

Entre esos proyectos editoriales, el más importante y numeroso es la colección publicada por Espasa-Calpe bajo el título "Vidas Españolas e Hispanoamericanas del Siglo XIX" (1929-1942), una serie de biografías concebida por Ortega y Gasset y dirigida por el granadino Melchor Fernández Almagro ${ }^{2}$. A diferencia del resto de

\footnotetext{
${ }^{2}$ Fernández Almagro (1883-1966) fue uno de los críticos más asiduos en las publicaciones culturales tanto anteriores como posteriores a la guerra civil (Revista de Occidente, El Sol, La Gaceta Literaria, La Voz, Verso y Prosa, Ya, ABC, etc.). Participó en los actos de homenaje a Góngora de 1927 y fue de los primeros en hablar de la generación del 27 ("Nómina incompleta de la joven literatura", Verso y Prosa, enero de 1927). Como ensayista destacan sus obras históricas sobre el siglo XIX.
} 
colecciones, las cincuenta y nueve biografías que configuran el proyecto se inscriben en unas coordenadas específicas que le confieren una mayor coherencia: por una parte, la delimitación a personajes decimonónicos del ámbito español e hispanoamericano y, por otra, el impulso de europeización del pensador madrileño, la razón vital y las diferentes consideraciones sobre la biografía que aparecen diseminadas a lo largo de sus artículos.

\section{La renovación biográfica europea a inicios del siglo $\mathrm{XX}$}

Los biógrafos más representativos de la renovación europea fueron Lytton Strachey en Inglaterra, André Maurois en Francia, Emil Ludwig en Alemania y Stefan Zweig en Austria. De acuerdo con Serrano Asenjo, las grandes aportaciones para la biografía de todos ellos son la adaptación de los postulados freudianos y de la concepción bergsoniana del tiempo, algo ya señalado por André Maurois en 1928. La nueva biografía atendió a las ambivalencias y contradicciones del ser humano, con el objetivo de desentrañar la conducta vital sin renunciar a ninguna faceta del hombre, tarea para la que fue capital ahondar en la existencia del inconsciente y de los diferentes sentimientos reprimidos. De esta manera, la biografía se convertía en desmitificación ${ }^{3}$, puesto que el personaje histórico ya no era tratado como el héroe de los retratos decimonónicos.

En cuanto a la influencia de Henri Bergson y de sus teorías acerca del tiempo, ésta se cifraba en la reconstrucción del tiempo de la existencia del biografiado. Esto es, acogieron para la revitalización del género el concepto de duración que el filósofo francés había desarrollado en su Ensayo sobre los datos inmediatos de la conciencia (1889) y sus reflexiones acerca de la intuición como componente no racional de la Introducción a la metafísica (1903). Las diferentes reflexiones que suponían las teorías bergsonianas en el campo biográfico se ven reflejadas en el Orlando (1928) de Virginia Woolf, subtitulado "una biografía"".

Aunque con cierta demora, la renovación europea fue conocida en España, tal como se observa en el artículo "Escuela de Plutarcos" de Antonio Marichalar, crítico y autor de una de las vidas de Espasa-Calpe: "Con la reciente moda de las

\footnotetext{
${ }^{3}$ En este sentido, Ira Bruce Nadel argumenta en Biography: Fiction, Fact \& Form (1985) que la biografía reconstruye al tiempo que deconstruye, lo cual dificulta la armonía de su naturaleza factual y literaria: "Biography is essentially a demythologizing form. Consistently, it functions to correct, restate or reinterpret false or distorted accounts of the subject." (p. 177).

${ }^{4}$ Virginia Woolf abordó la labor biográfica en el artículo "The New Biography” (1927) y en "The Art of Biography" (1939), así como en otras obras como Flush (1933) y la semblanza sobre Roger Fry (1940). Atendiendo a la prensa del periodo, sus reflexiones eran poco conocidas por los "aprendices de biógrafos" españoles, por lo que difícilmente influyó en la renovación biográfica española.
} 
biografías se ha conseguido, por lo menos, alguna renovación de patrones: ya no se cita como sempiterno modelo a Boswell, se citan a Maurois o Lytton Strachey.",

Como se ha indicado anteriormente, el primero en renovar la concepción tradicional de la biografía fue Strachey ${ }^{6}$. A pesar de ser el precursor, sólo teorizó sobre el género en el breve prólogo de los Victorianos eminentes (1918). En él sostenía que la biografía inglesa nunca había tenido una tradición como la francesa, ya que la tarea se había relegado a los aprendices de letras, sin admitir que tan difícil es escribir una buena vida como vivirla. Strachey dejaba atrás las biografías decimonónicas y victorianas para escribir unas vidas más sintéticas, apartadas de la moralización y marcadas por la ironía. Tal como él defendía en ese prólogo, la elección de los temas era ilustrativa, antes que explicativa, por lo que entre sus premisas se encontraban la brevedad libre de todo lo redundante y nada significativo y la libertad de espíritu, ya que el biógrafo no debía hacer cumplidos, sino exponer los hechos: "desapasionada, imparcialmente y sin intenciones ulteriores" $"$.

Otro de los escritores responsables de la renovación del género biográfico fue el alemán Emil Ludwig, que en 1920 escribió Goethe: historia de un hombre ${ }^{8}$. El objetivo de sus obras biográficas era contribuir a lo que él denominaba, con gráfica expresión, "la comprensión del corazón humano". Llegó a ser tratado como un creador de biografías en serie por su vasta producción biográfica y sus teorizaciones acerca de la revitalización del género también fueron, en cierta medida, contraproducentes. El problema radicaba en la etiqueta de "biografía novelada", entendida peyorativamente por parte de la crítica española9. Asimismo, para

\footnotetext{
${ }^{5}$ A. Marichalar (1927), p. 387.

${ }^{6}$ Lytton Strachey formó parte del grupo de Bloomsbury. Además de los Victorianos eminentes, conjunto de cuatro biografías de personajes de la generación precedente - el cardenal Manning, la enfermera Florence Nightingale, el pedagogo y humanista Thomas Arnold y el general Charles Gordon-, publicó otras biografías como La Reina Victoria (1921), Isabel y Essex (1928) y Retratos en miniatura (1931).
}

${ }^{7}$ L. Strachey (1989), p. 25.

${ }^{8}$ En su extensa nómina de biografiados se encuentran Juana la Loca, Napoleón, Bismarck, Stalin, Cleopatra, Bolívar, Freud, Beethoven, Maquiavelo, Leonardo, Balzac y Rembrandt. En la reseña que Juan Chabás — autor para la colección de Espasa-Calpe de Juan Maragall: poeta y ciudadano (1935) - realizó sobre la traducción de Ricardo Baeza en la editorial Juventud, éste destacaba precisamente el equilibrio entre pasión y entusiasmo de una biografía dispuesta como creación novelística (p. 142).

${ }^{9}$ También André Maurois había utilizado este marbete en el prólogo a Ariel o la vida de Shelley (1923), aunque en sus Memorias (1941) negara haberlo empleado: "Al contrario, había dicho que una biografía no debe inventar un hecho ni una conversación, pero que puede y debe disponer sus materiales auténticos como los de un novelista y dar al lector la sensación del descubrimiento de un mundo por un héroe que es el verdadero novelista." (1974a, p. 576). 
Ludwig la biografía era la tercera forma entre historia y ficción, después del drama histórico y la novela histórica. Pese a las polémicas suscitadas, el alemán compartía con el resto de biógrafos coetáneos el rechazo a las notas y los prejuicios morales.

Stefan Zweig ${ }^{10}$ fue uno de los opositores de la expresión "biografía novelada". Para él, la nueva biografía era la comunión entre la concepción psicológica y la poética de la historia. Esto es, el arte del biógrafo consistía para él en la composición de almas; un arte guiado por la intuición como fuente de conocimiento preponderante frente a los documentos. Por lo tanto, sus biografías también pretendían la humanización de los personajes históricos en oposición a la divinización. En relación con la novela, iba más allá al defender que la biografía debía reemplazarla, puesto que consideraba que la historia es más poética que la ficción. Sin embargo, esto no significaba que el biógrafo tuviera licencia para inventar, sino que sus libertades actuaban en el campo de la interpretación.

Finalmente, otro de los grandes renovadores del género, como apuntaba Antonio Marichalar, fue André Maurois — seudónimo de Émile Herzog- ${ }^{11}$. Además de servir de modelo para los nuevos biógrafos, el francés ofreció una reflexión sobre la biografía moderna —iniciada según Nicolson en 1907 y según Virginia Woolf en 1910 - en Aspectos de la biografía. Con este ciclo de seis conferencias pronunciadas en el Trinity College, de Cambridge, en mayo de 1928, Maurois pretendía complementar los Aspectos de la novela que Edward Morgan Foster había ofrecido, también al amparo de la fundación Clark, el año anterior. El escritor francés se oponía en esas disertaciones a Harold Nicolson, quien en El desarrollo de la biografía inglesa (1928) se manifestaba contrario a considerar la biografía como una obra de arte.

En este ensayo sobre "la biografía moderna", el autor de Ariel indagaba en las características del género a partir del cambio vivido en la Inglaterra de principios del siglo XX: la invasión de la psicología y la moral, el sentido de la complejidad y de la movilidad humanas fruto de las teorías de Henry Bergson y de los progresos de la física y la biología modernas, y la inquietud propia de una "época de dudas". Todo ello se traducía en el género biográfico, en primer lugar, en la "valiente busca de la verdad"; en segundo lugar, en la "inquietud por la complejidad de la persona"; $\mathrm{y}$, finalmente, en la preferencia de los lectores por esas biografías más humanas que

${ }^{10}$ Entre sus biografías se encuentran Tres maestros. Balzac, Dickens y Dostoievski (1920), Fouché, el genio tenebroso (1929), María Antonieta (1932), María Estuardo (1934), Erasmo de Rotterdam (1934) y Montaigne (publicado póstumamente en 1944), además de las semblanzas sobre Fernando de Magallanes (1938) y Américo Vespucio (1940) y otros ensayos con el tema histórico y biográfico como telón de fondo. El austriaco fue uno de los biógrafos más influyentes como prueba el homenaje que le rindió Benjamín Jarnés en Stefan Zweig, cumbre apagada (1942).

${ }^{11}$ Su Ariel (1923) fue una de las nuevas biografías que logró mayor difusión. También escribió las vidas de Disraeli (1927), Byron (1930) y Chateaubriand (1938), entre otras. 
"le presentan un personaje que también ha sido un ser dividido"12. Estos factores derivaban en la complejidad por combinar arte y ciencia, forma y contenido. Maurois sostenía que la biografía es un medio de expresión, puesto que "será, en cierto modo, una autobiografía disfrazada de biografía" ${ }^{3}$. Asimismo, el lector también buscaba en estas obras un modo de manifestación al acercase a una existencia real y mimetizarse con ella. En contraposición al novelista, el biógrafo tenía más dificultad en componer porque no podía dar cuenta de la síntesis entre vida interior y vida aparente ${ }^{14}$, ni poseía libertad para moldear a los personajes. A pesar de ello, "Cuando el Homo Biographicus cae en manos de un doctor hábil, éste puede, con inyecciones apropiadas, comunicarle esta vida interior tan característica del Homo Fictus y ello sin perjudicar la verdad." 15 Además de analizar el fenómeno de la nueva biografía, el autor establecía en su ensayo una serie de reglas para convertirla en una obra de arte: seguir un orden cronológico que expusiera el desarrollo progresivo del alma, dejar que la historia figurara sólo como telón de fondo, elegir los detalles relevantes para la lectura, narrar con objetividad y saber transmitir el ritmo de esa vida. Gracias a esta última consideración acerca del ritmo, Maurois dignificaba la biografía al poder poseer ésta valor poético ${ }^{16}$.

\section{Las "Vidas Españolas e Hispanoamericanas del Siglo XIX", culmen del fenómeno en España}

El fenómeno de la nueva biografía llegó a España a finales de los años veinte, momento en el que se tradujeron biografías y estudios literarios extranjeros hasta el punto de generarse ciertos recelos ante la posibilidad de que se acabaran conociendo mejor los personajes históricos foráneos que los propios, hecho que pudo servir a Ortega de estímulo para poner en marcha su proyecto editorial ${ }^{17}$.

Esas traducciones llegaron a España con cierta demora. Por ejemplo, la biografía del general Gordon por Strachey fue publicada, con una década de diferencia respecto al original, en la primavera de 1928 en Revista de Occidente. La revista dirigida por Ortega y Gasset dio cuenta de la recepción del auge de la biografía al reseñar buena parte de las aparecidas en las colecciones francesas "Le Roman des Grandes Existences", de la casa Plon, y "Vies des Hommes Illustres", de la Nouvelle Revue Française. Precisamente los críticos encargados de esos comentarios fueron pocos meses después los biógrafos de la colección de Espasa-Calpe.

${ }^{12}$ A. Maurois (1974b), pp. 1198-1203.

${ }^{13}$ A. Maurois (1974b), p. 1248. La identificación entre biógrafo y biografiado sigue siendo objeto de análisis de las biografías literarias. Cfr.: I. Nadel (1985), pp. 119-150 y M. Benton (2009), pp. 1-4 y 28-29.

${ }^{14}$ A. Maurois (1974b), p. 1279.

${ }^{15}$ A. Maurois (1974b), p. 1288.

${ }^{16}$ A. Maurois (1974b), p. 1222.

${ }^{17}$ Cfr. A. Rodríguez Fischer, 1991. 
Uno de ellos es, de nuevo, Antonio Marichalar, cuyo artículo "Las 'vidas' y Lytton Strachey" (1928) precedió a la vida del general Gordon. En él señalaba que los lectores estaban ávidos de encontrar liberación y refugio en otras existencias más interesantes y apuntaba que el fenómeno correspondía al incremento de estudios psicológicos en torno al problema de la personalidad. Según Marichalar, para el lector medio, cada novela era reductible a una vida, a un diario, así ocurría con Emma Bovary o Julian Sorel. Además, aludía al carácter autobiográfico que puede entrañar cualquier novela ${ }^{18}$. En cuanto a Strachey, además de elogiar su maestría para escribir la historia, admiraba su habilidad para trazar las vidas como un psicólogo - y no un erudito- que aportaba el dato oportuno y decisivo ${ }^{19}$.

Otro de los artículos capitales para la cuestión, también aparecido en Revista de Occidente, es "Nueva quimera del oro", firmado por Benjamín Jarnés en 1929, el mismo año en el que se publicó en la colección de las "Vidas" su primera biografía: Sor Patrocinio: la monja de las llagas. En él, reseñaba el Aspectos de la biografía de Maurois, lo cual demuestra que conocían las inquietudes del francés acerca de la "dificultad de acercarnos a una personalidad" 20 , así como el modelo de biografías europeas. La confirmación se encuentra en la nota preliminar a la biografía sobre la religiosa española: "Voz de un artista, voz de un hombre capaz de transmitir en vivo la lejana vibración de una personalidad." ${ }^{21}$ A Jarnés, como compartirán el resto de escritores del entorno orteguiano, le interesaba la biografía moderna trazada por Maurois en tanto que dejaba de ser un producto de documentación de materiales mal digeridos para ser una obra de arte, una aventura; y el biógrafo, un "poeta de la historia" que se lanzaba a la "perenne quimera del oro humano"22.

Meses más tarde, en el número de noviembre, de nuevo Benjamín Jarnés publicó en la revista orteguiana "Vidas oblicuas". En este artículo se refería a Efigies, una serie biografías de algunos literatos del siglo XIX - Baudelaire, Barbey d'Aurevilly, Gérard de Nerval, Lautreamont, etc.- escritas por Ramón Gómez de la Serna, al que consideraba precursor de los "actuales biógrafos españoles"23. Jarnés abordaba alguna de las claves de la nueva biografía, como la renuncia a la profusión del dato y la tarea preponderante del biógrafo para transfigurar la vida

${ }^{18}$ Así lo defendían también Pío Baroja, Ramón Gómez de la Serna o Rosa Chacel, que, en La confesión (1971) argumenta que las biografías de Cervantes, Galdós o Unamuno están en su propia obra.

19 A. Marichalar (1928), p. 354.

${ }^{20}$ B. Jarnés (1929a), p. 118.

${ }^{21}$ B. Jarnés (1929b), p. 11.

${ }^{22}$ B. Jarnés (1929a), p. 122.

${ }^{23}$ Gómez de la Serna fue uno de los pioneros en la renovación del género biográfico en España con títulos como Goya (1928), Azorín (1930) o El Greco. El visionario de la pintura (1935). En el prólogo a Efigies el escritor comentado por Espina afirmaba, como en otras numerosas ocasiones, no encontrar diferencia entre el concepto de novela y el de biografía. 
relatada, reiterando la idea de Maurois de que la biografía escrita por un artista sería siempre una autobiografía, en tanto que medio de expresión ${ }^{24}$.

La Revista de Occidente no fue la única en hacerse eco del auge biográfico. También tuvieron un papel destacado publicaciones periódicas como $A B C, L a$ Gaceta Literaria y El Sol, el cual incluyó desde 1928 un apartado para la reseña de biografías y publicó varios artículos relacionados con el fenómeno ${ }^{25}$. De este modo, el aparato crítico-literario difundió las novedades europeas al tiempo que anunciaba las primeras colecciones motivadas por la moda ${ }^{26}$. Todos coincidían en la escasa práctica del género biográfico en la literatura española, carencia que era necesario suplir para poder parangonarse con la corriente europea.

Así lo vio Ortega y Gasset, que ya en "Sobre unas 'memorias" (1927) reflexionaba sobre la escasez de biografías en nuestras letras y la achacaba a la complacencia en la vida que conllevaba el género y que no se daba en España. La falta de apego por la vida está en consonancia con la razón vital que conforma su pensamiento: el ser humano no está separado de la realidad, es un "yo y mi circunstancia", como diría en las Meditaciones del Quijote (1914); un hacerse que parte de la tensión entre la vocación y la circunstancia. Para ello, era necesario aproximarse a la vida de los otros, y es en este sentido en el que la nueva biografía adquiría un prisma filosófico en el marco de la colección de Espasa-Calpe.

Para Ortega, tal como se desprende en "A una edición de sus obras" (1932), toda vida es misterio y labor de desciframiento de las pulsiones que guían sus acciones. La aproximación a ello - como en el caso de los nuevos biógrafos- está impulsada por una voluntad de comprensión y de entendimiento, no de moralización. Por consiguiente, una de las pretensiones de la colección estribaba en la necesidad de conocer otras vidas y sumergirse tras ello en la propia, de "fomentar la porosidad de mis lectores hacia el prójimo" "27. Con la razón vital se pretendía dar un giro a la depresión y disminución que, según él se había percatado, sentían los españoles ante las vidas de otras personas, y encaminar esa actitud hacia la comprensión de las circunstancias y el enriquecimiento de la perspectiva.

${ }^{24}$ B. Jarnés (1929c), p. 253.

${ }^{25}$ Destacan los artículos de Ricardo Baeza, "El nuevo arte biográfico" (29-04-1927), "El arte de la biografía en Inglaterra" (02-05-1927), "Últimas consideraciones sobre el arte de la biografía" (07-05-1927) y "Este florecimiento de la literatura biográfica (05-05-1927); Ramón Pérez de Ayala, "Carencia de biografías y autobiografías. Sobre el individualismo ibero" (1-12-1927); y Enrique Díez-Canedo, "El afán de las "vidas"” (18-10-1928).

${ }^{26}$ En Plutarco de moda: la biografia moderna en España (1900-1950) (2009), Manuel Pulido Mendoza ofrece una extensa catalogación de las biografías europeas y españolas que se incorporaron al auge biográfico, ampliando las ya señaladas por Serrano Asenjo (2002) y Fernández Cifuentes (1982).

${ }^{27}$ J. Ortega y Gasset (1983a), p. 344. 
El requerimiento de modelos volvía a ser el tema recurrente de "Sobre las carreras" (1934). Pero si hay un artículo clave para entender la importancia del acercamiento a las vidas pasadas ése es "Pidiendo un Goethe desde dentro" (1932). Contrario a las biografías realizadas sobre el escritor romántico desde una óptica exterior, Ortega proponía invertirla y ofrecer un Goethe desde el interior para comprender su proyecto vital - circunstancia, vocación y destino-. Sin embargo, no se trataba de acogerse meramente a la psicología: el biógrafo debía servirse de esta disciplina, sin olvidar la fisiología; pero lo que realmente adquiría relevancia era la sumersión del hombre en su circunstancia, en lo que no es él, puesto que el "dinamismo dramático entre ambos elementos - yo y mundo- es la vida" ${ }^{28}$. Esa vida sería más o menos auténtica en proporción a la fidelidad respecto a la vocación. Es a ello a lo que debía atender la biografía: a determinar o descubrir la vocación vital y la fidelidad al destino; esto es, al sentimiento trágico de la condición humana ${ }^{29}$. Y añadía en consonancia: "La biografía es eso: sistema en que se unifican todas las contradicciones de una existencia"30.

Con estas doctrinas como trasfondo, las coordenadas de las vidas de la colección eran dos: por una parte, la reducción temporal al periodo decimonónico y, por otra, la reducción geográfica en un principio al ámbito nacional ${ }^{31} \mathrm{y}$, posteriormente, a partir del undécimo número, ampliada a Hispanoamérica ${ }^{32}$. Enrique Serrano Asenjo

${ }^{28}$ J. Ortega y Gasset (1932), p. 10.

${ }^{29}$ Ortega se ancla en la realización del proyecto vital, difiriendo parcialmente de la teoría sobre el sentimiento trágico expuesta por Miguel de Unamuno en su ensayo de 1912. Para el bilbaíno, el sentimiento trágico de la vida estriba en la sed de eternidad e inmortalidad, anhelo en contradicción con la razón y la ciencia.

${ }^{30}$ J. Ortega y Gasset (1932), p. 23.

${ }^{31}$ En un inicio se tituló "Vidas Españolas del Siglo XIX”. El mexicano Jaime Torres Bodet, en su reseña sobre la colección en Revista de Occidente, veía en esas figuras una revisión indispensable para asentar un estado realmente democrático: "Ahora, en un minuto de revisión nacional de valores, cuando la vida necesita apoyarse en otra cosa que la seguridad de la rapidez adquirida, una generación de biógrafos no sólo se adapta a un tono convencional del gusto del mundo. Responde a una necesidad íntima del país. Implica la madurez de su conciencia crítica." (1930, p. 281).

${ }^{32}$ Melchor Fernández Almagro había manifestado desde un inicio su voluntad de extender las vidas a personajes hispanoamericanos, como se constada en el epistolario con Guillermo de Torre - Cartas cruzadas entre Guillermo de Torre y Melchor Fernández Almagro (1922-1966) (2008) - , que colaboró en la colección como mediador y consejero al ser el director de publicidad de la delegación de Espasa-Calpe en Argentina. Las razones definitivas de la ampliación se encuentra en el segundo viaje de Ortega a Argentina (1928), con la consabida polémica suscitada por los artículos "La Pampa...promesas" y "El hombre a la defensiva", ambos publicados en La Nación de Buenos Aires en 1929. La estrategia comercial de buscar lectores americanos se apoyaba en la necesidad orteguiana de disponer de modelos vitales y de conocer la historia para no repetir los errores pasados. 
defiende que seguramente la elección del siglo XIX se deba a la conflictiva relación de los españoles con el siglo anterior ${ }^{33}$. Desde las Meditaciones del Quijote, Ortega se refirió en varias ocasiones a la obnubilación de la vida individual por parte de la vida social predominante en la centuria precedente ${ }^{34}$. Según el pensador, la política y los problemas de la vida social habían relegado la merecida atención sobre la vida individual, algo a lo que también había contribuido el sistema racional positivista al anular la voluntad del hombre y su vitalidad. En consecuencia, otro de los objetivos de la colección podría ser rescatar esas vidas individuales para contemplar su drama vital. Asimismo, la reconstrucción histórica que permitían las cincuenta y nueve vidas de la colección se debía a la importancia del Romanticismo como primera contestación al imperio de la razón y a la comprensión de los acontecimientos de la política española decimonónica para poder superar la lucha bipartidista entre liberales y reaccionarios, y, con ello, reorientar los hechos futuros. De este modo, el proyecto editorial es una pieza más en su voluntad de regeneración, puesto que sólo a partir del conocimiento de los hechos y las vivencias pretéritas se lograría construir un futuro libre de los errores pasados ${ }^{35}$.

En lo referente a los biógrafos, la profundización en las psicologías de personajes históricos, desde literatos a políticos, pasando por toreros o caudillos de la independencia hispanoamericana, permitía a los jóvenes autores de la novela deshumanizada disponer de un escenario donde practicar su prosa ${ }^{36}$. Ejemplo de ello es el testimonio de Rosa Chacel en "Respuesta a Ortega. La novela no escrita" (1956). En ese artículo, la escritora, encomendada de novelar la vida de la amante de Espronceda Teresa Mancha ${ }^{37}$, rememoraba la petición de Ortega como una

${ }^{33}$ E. Serrano Asenjo (2002), p. 108.
${ }^{34}$ J. Ortega y Gasset (1990), p. 67.

35 También debe atenderse a lo expuesto por Fernández Almagro en su reseña de Luis Candelas acerca del siglo XIX español: "Su fisonomía y andanzas habrán de fijarse mediante el doble tiempo de acumulación y selección que representa en cada caso el examen de vidas representativas: la del tribuno, la del cabecilla, la del torero, la del caballero de industria, la del poeta... De aquí la oportunidad de Espasa-Calpe al planear una serie, ya en marcha, de 'Vidas españolas del siglo XIX', sin dejar fuera - porque no se trata de un Plutarco que edifique - personaje alguno de interés específico, por esquinado que esté contra la ley ya que la Historia, en efecto, no es una moralidad ni un ejemplo: es nada más y nada menos que una gran aventura." (1930, p. 1).

${ }^{36}$ Se ha relacionado la aparición de la biografía vanguardista con el "nuevo romanticismo" defendido por José Díaz Fernández en su ensayo homónimo de 1930. Asimismo, se ha interpretado la iniciativa biográfica de Ortega como la consecuencia del fracaso de la innovación novelística propuesta en La deshumanización del arte e Ideas sobre la novela (1925). Cfr. F. Soguero García, 2000.

${ }^{37}$ Pese a la encomienda, Chacel no pudo finalizar la biografía hasta $1936 \mathrm{y}$, debido al estallido de la guerra civil y a las complicaciones derivadas de ésta, se publicó en Buenos Aires en 1941. 
reconciliación con la realidad que debía dar como resultado la valoración del recuerdo $^{38}$. La colección, por lo tanto, extendía la voluntad pedagógica también a los discípulos orteguianos. En otro artículo posterior, "Reflexión de un largo camino" (1993), la vallisoletana también mencionaba que el filósofo perseguía con esas biografías "paliar la deshumanización, con la esperanza de que entre los jóvenes prosistas surgiera un rehumanizador que la rehumanizase." 39

Pese a la heterogeneidad de biógrafos - no sólo escritores del "Nova Novorum", sino también políticos e historiadores de la tendencia historiográfica liberal, autores consagrados como Pío Baroja o José María Salaverría, etc.-, en varios prólogos o notas preliminares de la serie se observan las deudas orteguianas. Ejemplo de ello son las consideraciones del conde de Romanones, autodenominado "aprendiz de biógrafo", en su Sagasta o el político:

No son los datos biográficos del gran caudillo liberal lo que puede importar en mayor grado al lector de VIDAS ESPAÑOLAS DEL SIGLO XIX; sin duda, lo que esta Biblioteca se ha propuesto es dar a conocer, tanto como la vida pública, la vida íntima de las figuras más interesantes de aquella centuria, descubriendo el resorte de sus acciones, la pasión que las movió, el ambiente que respiraron, el ritmo, en fin, de toda su época. ${ }^{40}$

Resuenan asimismo las ideas del filósofo sobre la vida como misterio en el inicio de la biografía que Alfons Maseras y Carles Fagés de Climent elaboran sobre el pintor catalán Marià Fortuny:

Toda vida es una aventura. Toda existencia es un enigma. Lo son las vidas llanas y apacibles, que parecen ignorar el dolor. Lo son, con más razón, las vidas inquietas y tumultuosas, y las que se proyectan más hacia dentro del alma que hacia el mundo exterior, como suelen ser las de quienes han nacido con el demonio del arte en el cuerpo. ${ }^{41}$

Algunos de esos prólogos contienen, además, reflexiones sobre la relación existente en algunos retratos entre el biógrafo y el biografiado, las dificultades derivadas de la redacción de las biografías y las reflexiones acerca de los límites del género y sus concomitancias con la historia y la biografía. Por ejemplo, sobre la incursión novelística y creativa, Pío Baroja ${ }^{42}$ es de los que se muestra más taxativo:

\footnotetext{
${ }^{38}$ R. Chacel (1956), p. 117.

${ }^{39}$ R. Chacel (1993), p. 416.

${ }^{40}$ C. de Romanones (1930), p. 17.

${ }^{41}$ A. Maseras y C. Fagés de Climent (1932), p. 7.

${ }^{42}$ Baroja aportó a la colección Avinareta, o La vida de un conspirador (1931), biografía en la que sintetiza parte de la existencia del conspirador protagonista de Las memorias de un hombre de acción, y, más tarde, la vida del aventurero Van Halen (1933).
} 
Yo no sé si en una biografía puramente histórica como ésta la tarea del escritor debe consistir en estilizarla y en adornarla o únicamente en buscar datos para aclarar sus puntos obscuros. Yo he optado por esto último dentro de la pobreza de mis medios.

En la Historia no sé cómo se puede evitar el copiar; únicamente en los comentarios es posible hacer algo original; en lo demás parece imposible. Yo he copiado, cuando he tenido que hacerlo, sin escrúpulo. ${ }^{43}$

Pese a esta afirmación, no cabe duda de que un novelista de su magnitud aportó una marcada influencia literaria a las vidas de sus biografiados. Más acorde con los postulados novelescos se muestra el argentino Arturo Capdevila en su La Santa Furia del Padre Castañeda:

Por lo restante, no deseo averiguar si mi trabajo pertenece más a la novela que a la historia. Parten límites la historia y la novela en la biografía. Mas presumo que este mi libro será tanto más histórico cuando más novelesco parezca. Quiero decir que he avanzado sin miedo hacia la novela, en busca de la mayor verdad posible para bien de un personaje profundamente novelesco. ${ }^{44}$

A grandes rasgos, puede afirmarse que, en cuanto a las concomitancias de la colección dirigida por Fernández Almagro frente a los cauces europeos, se comparte la indagación en el pasado inmediato, lo cual supone que el fenómeno sea tanto literario como social, y existe también una desvinculación historiográfica -al menos en la mayoría de biografías de la serie-, al mismo tiempo que se dialoga sobre las fronteras con otros géneros. En cuanto al papel de Ortega, la colección adquiere mayor hondura si se relaciona con su magisterio intelectual y su sistema filosófico, además de complementar la definición del concepto de deshumanización.

En conclusión, la colección "Vidas Españolas e Hispanoamericanas del Siglo XIX" proporciona un amplio abanico de análisis, sobre todo si se tiene presente que la duración de la colección, de 1929 a 1942, coincide con la profusión de biografías constatable en las publicaciones periódicas de la época. Una de las posibles vías de investigación es su papel en el conjunto de las empresas culturales de José Ortega y Gasset. Otra, su importancia en el apogeo de la nueva biografía en España. Todo ello sin olvidar la nueva perspectiva que aporta a uno de los periodos literarios más proclives del panorama español, justo antes del declive de la guerra.

\footnotetext{
${ }^{43}$ P. Baroja (1933), p. 7.

${ }^{44}$ A. Capdevila (1933), pp. 7-8.
} 


\section{OBRAS CITADAS}

BAROJA, Pío: Juan Van Halen, el oficial aventurero, Madrid, Espasa-Calpe, 1933.

BENTON, Michael: Literary Biography: An Introduction, Chichester, WileyBlackwell, 2009.

CAPDEVILA, Arturo: La Santa Furia del Padre Castañeda, Madrid, Espasa-Calpe, 1933.

CHABÁS, Juan: "Ludwig: Napoleón", Revista de Occidente, 79 (enero 1930), pp. 140-143.

CHACEL, Rosa: "Respuesta a Ortega: la novela no escrita", Sur, 241 (julio-agosto 1956), pp. 97-119.

-: Obra Completa. Artículos I, Volumen III, Valladolid, Excma. Diputación provincial de Valladolid, Centro de Estudios Literarios, Fundación Jorge Guillén, 1993.

ESPINA, Antonio: "Vidas oblicuas", Revista de Occidente, 77 (noviembre 1929), pp. 251-256.

FERnÁndeZ Almagro, Melchor: "El 'Luis Candelas' de Antonio Espina”, La Gaceta Literaria, 74 (15 de enero de 1930), p. 1.

FERNÁNDEZ CIFUENTES, Luis: Teoría y mercado de la novela en España: del 98 a la República, Madrid, Gredos, 1982.

JARNÉS, Benjamín: "Nueva quimera de oro", Revista de Occidente, 67 (enero 1929a), pp. 118-122.

-: Sor Patrocinio, la monja de las llagas, Madrid, Espasa-Calpe, $1929 \mathrm{~b}$.

—: "Vidas oblicuas", Revista de Occidente, 77 (noviembre 1929c), pp. 251-256.

MARICHALAR, Antonio: "Escuela de Plutarcos", Revista de Occidente, 51 (septiembre 1927), pp. 387-389.

-: "Las 'vidas' y Lytton Strachey", Revista de Occidente, 57 (marzo 1928), pp. 343-358.

MASERAS, Alfons; FAGÉS DE Climent, Carles: Fortuny, la mitad de una vida, Madrid, Espasa-Calpe, 1932.

MAUROIS, André: Memorias, en Obras Completas, IV. Memorias y ensayos, Barcelona, Plaza \& Janés, 1974a, pp. 417-747.

-: Aspectos de la biografia, en Obras Completas, IV. Memorias y ensayos, Barcelona, Plaza \& Janés, 1974b, pp. 1179-1289.

NADEL, Ira Bruce: Biography: Fiction, Fact and Form, Londres, Macmillan, 1985.

ORTEGA Y GASSET, José: "Pidiendo un Goethe desde dentro", Revista de Occidente, 106 (abril 1932), pp. 1-41.

-: "A una edición de sus obras", Obras completas. VI, Madrid, Revista de Occidente, 1983a, pp. 342-354.

—: Meditaciones del Quijote, Madrid, Cátedra, 1990.

Pulido MendozA, Manuel: Plutarco de moda: la biografía moderna en España (1900-1950), Mérida, Editora Regional de Extremadura, Servicio de Publicaciones de la Universidad de Extremadura, 2009. 
RODRÍGUEZ FISCHER, Ana: "Un proyecto de Ortega y Gasset: la colección Vidas españolas e hispanoamericanas del siglo XIX", Scriptura, 6-7 (1991), pp. 133-144. RomANONES, (Conde de): Sagasta o el político, Madrid, Espasa-Calpe, 1930.

SERRANO ASENJO, Enrique: Vidas oblicuas: Aspectos teóricos de la nueva biografía en España (1928-1936), Zaragoza, Prensas Universitarias de Zaragoza, 2002.

SOGUERO GARCÍA, Francisco Manuel: "Los narradores de vanguardia como renovadores del género biográfico: aproximación a la biografía vanguardista", en Francis Lough (ed.), Hacia la novela nueva: Essays on the Spanish AvantGarde Novel, Oxford, Peter Lang, 2000, pp. 199-217.

STRACHEY, Lytton: Victorianos eminentes, Madrid, Aguilar, 1989.

TORRES BODET, Jaime: "Vidas españolas del siglo XIX", Revista de Occidente, 80 (febrero 1930), pp. 281-293. 